\title{
Cytotoxic and Antioxidant Effects in Various Tissue Extracts of Plumbago zeylanica: Implications for Anticancer Potential
}

\author{
Balachandran Karpaga Raja Sundari ${ }^{*}$, Srivani Telapolu², Bilikere S. Dwarakanath ${ }^{3}$, Sadras. P. Thyagarajan ${ }^{4 *}$
}

\section{Balachandran Karpaga Raja Sundari ${ }^{*}$, Srivani Telapolu², Bilikere S. Dwarakanath ${ }^{3}$, Sadras. P. Thyagarajan ${ }^{4 *}$}

'Ph.D. DST-National Post-Doctoral Fellow, Herbal and Indian Medicine Research Laboratory, Central Research Facility, Sri Ramachandra University, Porur, Chennai-600116, Tamil Nadu, INDIA.

${ }^{2} P h . D$ Scholar, Herbal and Indian Medicine Research Laboratory, Central Research Facility, Sri Ramachandra University, Chennai-600116, Tamil INDIA.

${ }^{3}$ Ph.D., Professor (Research), Central Research Facility, Sri Ramachandra University, Chennai-600 116, Tamil Nadu. INDIA.

${ }^{4}$ Ph.D., M.D., D.Sc. Professor of Eminence \& Dean (Research), Central Research Facility, Sri Ramachandra University, Chennai-600116, Tamil Nadu, INDIA.

\section{Correspondence}

B. Karpaga Raja Sundari and S.P.Thyagarajan, Sri Ramachandra University, Porur, Chennai-600116, Tamil Nadu. INDIA.

Phone numbers 9952850044 ; Ph: 0444592687

E-mail: biokarpagam@gmail.com; deanresearch@sriramachandra.edu.in

History

- Submission Date: 02-06-2017;

- Review completed: 15-06-2017

- Accepted Date: 02-07-2017

DOI : 10.5530/pj.2017.5.111

Article Available online

http://www.phcogj.com/v9/i5

Copyright

(C) 2017 Phcog.Net. This is an openaccess article distributed under the terms of the Creative Commons Attribution 4.0 International license.

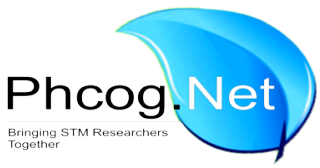

\begin{abstract}
Introduction: Complex natural products are emerging as a potent alternate and complement in anticancer therapies due to its multiple mechanisms of action and minimal effects on nontarget cells/tissues. Some of the traditional herbal formulations contain Plumbago zeylanica $\mathrm{L}$, (commonly known as Chitraka or Chitramoolam) to treat various disorders for centuries in Africa and Asia. Methods: The quantity of Plumbagin was detected in different tissues of P. zeylanica through HPTLC analysis. We evaluated and compared the alcoholic tissue extracts of leaf, stem and root of $P$. zeylanica with standard pure Plumbagin for its in vitro cytotoxic effects (metabolic viability; MTT assay) in A549 Lung cancer cells and antioxidant potential (DPPH free radical scavenging and total phenol content). RNA sequencing and transcriptome analysis was performed in the most potent tissues of $P$. zeylanica demonstrating efficient pharmacological activity. Results: The root extract containing $1.3 \%$ of plumbagin exhibited strongest scavenging potential with $50 \%$ radical scavenging $\left(\mathrm{IC}_{50}\right.$ value of $\left.3.99 \mu \mathrm{g}\right)$ in comparison with $35.85 \mu \mathrm{g}$ in stem $(0.2 \%$ Plumbagin) and $18.06 \mu \mathrm{g}$ in leaf with $0.00007 \%$ Plumbagin. The in vitro cytotoxicity in A549 cells also showed that the root extract was most potent with an IC50value of $164.5 \mu \mathrm{g}$ as compared to extracts from stem $\left(\mathrm{IC}_{50}=379.5 \mu \mathrm{g}\right)$ and leaf $\left(\mathrm{IC}_{50}=274.9 \mu \mathrm{g}\right)$. Conclusion: The strong antioxidant potential shown by the P. zeylanica extract demonstrates its ability to protect the non-target (normal) cells against oxidative stress, while the cytotoxic effects suggest that it could inhibit the growth of cancerous cells. Further, transcriptome analysis predicted the expression of potent gene transcripts coding for quinone biosynthesis in the root tissues of $P$. zeylanica.

Key words: Alcoholic Root Extract, A549 Cell Line, DPPH Assay, HPTLC Quantification, Plumba-
\end{abstract} gin, Transcriptome Analysis.

\section{INTRODUCTION}

Treatment of malignant diseases has remained a challenge to the medical community, despite advances in biomedical research, mainly due to refractoriness of tumors and limited normal tissue tolerance to therapies. Complementary and alternative therapies for the management of many diseases are spreading globally with increased use of herbal products in many countries. Recently, complex natural products have received more attention as anticancer agents, due to their potent pharmacological activity at low concentrations and minimal toxicity to normal cells. ${ }^{1}$ Plumbago zeylanica Linn.(Chitraka or Chitramoolam), which belongs to the family Plumbaginaceae is associated with huge pharmacological potential to treat several diseases. ${ }^{2,3}$ The roots of $P$. zeylanica $\mathrm{L}$. have been traditionally used in the Indian system of medicine for many years and its phyto-constituents is known to possess antiatherogenic, anticancer, cardiotonic, hepatoprotective and neuroprotective properties. ${ }^{4,5}$ The leaf extract also exhibit anticancer, antibacterial, antifungal and antitumor properties and used to treat tuberculosis, rheumatic pain, syphilis and skin diseases. ${ }^{6,7}$ Plumbagin (5-hydroxy-2-methyl-1,4-naphthoquinone) is the principle compound in P.zeylanica that has been shown to exert anticancer effects on many cancer cells. ${ }^{8,9,10}$

The biosynthesis and accumulation of secondary metabolites varies among populations, local races and even between different tissues of the same plant. ${ }^{11,12}$ Huge variations in the pharmacological activity have been observed between stem, leaf, flower and root tissues of Leucas aspera which arise due to difference in the phytochemical constituents. ${ }^{13}$ Similar spatial variations in phyto-constituents of medicinal plants have been observed in species of Sorbus decora ${ }^{14}$ and in Clinacanthus nutans. ${ }^{15}$ Hence, traditional system of medicine prefers to choose specific plant parts for mitigating different symptoms and treatment. ${ }^{16,17}$ Therefore investigating the variation in the active principles enriched in different plant parts is an important criterion to understand chemical constituents responsible for pharmaceutical potential.

Cite this article : Sundari BKR, Telapolu S, Dwarakanath BS, Thyagarajan SP. Cytotoxic and Antioxidant Effects in Various Tissue Extracts of Plumbago zeylanica: Implications for Anticancer Potential. Pharmacog J. 2017;9(5):706-12. 
The phytochemical and pharmacological activities of $P$. zeylanica have been studied extensively, revealing its ethano-botanical usage in traditional medicine. ${ }^{3}$ However, the complete metabolite profile and the transcriptome analysis of this species has not been carried out to determine its pool of active gene transcripts involved in deciphering the pharmacological function of phytomedicine. In recent years, the functional genomics approach supported by targetedmetabolite and transcriptome profiling has been widely used as an efficient tool for deciphering novel gene functions in phytomedicine. ${ }^{18}$ Owing to the rapid boom in cost effective high-throughput next generation sequencing technologies, a hot quest for sequencing the genomes and transcriptome of these life-saving medicinal plants have been instigated recently. ${ }^{19}$ Nevertheless, large-scale bio prospection approaches in genomics and transcriptomics of phytomedicine is still its underway for exploring novel potentially important plant species.

In the present study, we investigated the antioxidant and anti-proliferative potential in different tissues of P.zeylanica and compared with pure Plumbagin molecule to identify the most potent tissue specific phytoconstituent exhibiting pharmacological activity for anticancer therapeutic potential. HPTLC quantification method was employed to assess the phytochemical activity through quantitative determination of the main bio-active compound plumbagin in stem, leaf and root extract of P.zeylanica. Further, we also carried out RNA sequencing and transcriptome analysis in the more potent tissue of $P$. zeylanica to predict potential pathways and secondary metabolite compounds with pharmacological function.

\section{MATERIAL AND METHODS}

\section{Collection of plant material and authentication}

P. zeylanica was obtained from the medicinal plant garden of Irula Tribe Womens Welfare Society (ITWWS) Thandarai, Chengalpet and authenticated by Prof. Jayaraman, Plant Anatomist Botanists, Plant Anatomy Research Centre, Tambaram (PARC/2016/3562). A voucher specimen was deposited at the Herbal and Indian medicine Research Laboratory, Sri Ramachandra University, Chennai. The stem, leaf and roots of the plant was washed thoroughly, air dried, and ground into fine powder.

\section{Preparation of extracts}

Extraction of root, stem and leaf $(5 \mathrm{~g})$ involved cold maceration with ethanol for $24 \mathrm{~h}$ and the filtrate was collected. It was concentrated in a rotary vacuum evaporator at $60^{\circ} \mathrm{C}$. The percentage yield of stem, leaf and root was $0.44 \mathrm{~g} \mathrm{w} / \mathrm{w}, 0.45 \mathrm{~g} \mathrm{w} / \mathrm{w}$ and $0.3 \mathrm{~g} \mathrm{w} / \mathrm{w}$ respectively.

\section{Preparation of Plumbagin Standard:}

Standard Plumbagin (97\% purity) was purchased from Sigma-Aldrich, USA.

\section{Estimation of total phenolic content in extracts}

The total phenolic content in the extracts were estimated using the FolinCiocalteu method (Yu et al., 2002). Ethanolic extract of stem, leaf and root extract $(100,200 \mu \mathrm{g} / \mathrm{mL})$ were mixed with $2.5 \mathrm{ml}$ of $10 \%$ Folin-Ciocalteau's reagent $(\mathrm{v} / \mathrm{v})$ and neutralized by $2.0 \mathrm{ml}$ of $7.5 \%$ sodium carbonate. The final mixture was incubated at $45^{\circ} \mathrm{C}$ for $40 \mathrm{~min}$ and the absorbance was measured at $765 \mathrm{~nm}$ in a multi-mode reader (PerkinElmer Enspire, USA). The total phenolic content is expressed as gallic acid equivalent and experiments were assayed in triplicate.

\section{Quantitative determination of Plumbagin through HPTLC analysis}

Plumbagin content was estimated in ethanolic extracts of root, stem and leaf using Camag HPTLC system (CAMAG Scientific Inc, USA). The sample solutions were spotted as bands on pre-coated silica gel G 60 F254 $(20 \mathrm{~cm} \times 10 \mathrm{~cm}$ with $250 \mu \mathrm{m}$ thickness, E. Merck) with Hamilton
$100 \mu \mathrm{l}$ syringe plate on Camag Linomat-V applicator. The slit dimension was $6.00 \mathrm{~mm} \times 0.45 \mathrm{~mm}$ wherein the linear ascending development was performed in $20 \mathrm{~cm} \times 10 \mathrm{~cm}$, Camag twin trough glass chamber saturated with mobile phase containing toluene: ethyl acetate (9.5:0.5) at room temperature. The mobile phase was developed by trial and error method. After the plates were air-dried, photo-documentation was performed using CAMAG REPROSTAR 3at 265nm. HPTLC plate was scanned using Camag TLC Scanner-III at $419 \mathrm{~nm}$. A calibration plot was generated using the area values of peak and subjected to linear regression analysis. The extracts were spiked with the known amount of plumbagin to ascertain the presence of standard compound.

\section{Antioxidant Potential in different tissues}

The antioxidant activity of the extracts was evaluated against diphenyl2-picrylhydrazyl (DPPH) free radicals as per method given by Srirama

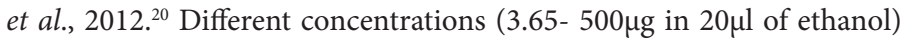
were prepared and mixed with $(180 \mu \mathrm{l}) 50 \mu \mathrm{M}$ DPPH. Plumbagin in different concentration $(0.83-100 \mu \mathrm{M})$ was used as the reference-standard. The reaction mixture was incubated for 30 minutes in dark at $37^{\circ} \mathrm{C}$, and the absorption was measured at $517 \mathrm{~nm}$ using the multi mode reader (PerkinElmer Enspire, USA). The free radical scavenging activity (RSA) was measured as a percentage of DPPH discoloration with the formula: $\% \mathrm{RSA}=[(\mathrm{Ac}-\mathrm{As}) / \mathrm{Ac}] \times 100$; where RSA: radical scavenging activity; Ac: absorbance of the negative control; As: absorbance of the plant sample.

\section{In vitro cytotoxic activity assay}

The effect of P.zeylanica extracts on A549 (human lung carcinoma cell line) was determined by the MTT assay. ${ }^{21}$ A549 cell line was obtained from National centre for Cell Science, Pune and cultured in Dulbeccos Modified Eagle Medium (DMEM) with 10\% Foetal Bovine Serum (FBS) supplemented with penicillin (5units/mL), streptomycin $(5 \mu \mathrm{g} / \mathrm{mL})$. Cells $\left(1 \times 10^{3}\right.$ cells) were seeded in96-well plate. After $80 \%$ confluence, cells were incubated with different concentrations of root, stem, leaf (15.62 to 1000 $\mu \mathrm{g} / \mathrm{ml})$ and plumbagin $(0.83$ to $100 \mu \mathrm{M})$ for $24 \mathrm{~h}$.After $24 \mathrm{~h}$ treatment, $50 \mu \mathrm{L}$ of MTT indicator ( $5 \mathrm{mg} / \mathrm{mL}$ in PBS) was added to each well and incubated at $37^{\circ} \mathrm{C}$ for $3 \mathrm{~h}$. Subsequently, $150 \mu \mathrm{L}$ of DMSO was added to solubilize the purple coloured formazan crystals. The optical density was measured at 570nm using a microplate reader (PerkinElmer Enspire, USA). The $\mathrm{IC}_{50}$ values of test compounds were determined using Graph Pad Prism v6.0 (GraphPad, San Diego, CA).

\section{RNA sequencing and Transcriptome analysis}

Total RNA was isolated from fresh root tissues of $P$. zeylancia plant using Spectrum Plant Total RNA isolation kit (Sigma-Aldrich, USA) according to manufacturer's instructions. The quantitative and qualitative analysis of the RNA samples was performed using Nanodrop 2000 and Qubit Fluorometer (Thermo Fisher Scientific, Wilmington, DE). RNA library preparation and sequencing was performed at Genotypic Technology's Genomics facility as per Ultra Directional Library Prep Kit protocol for Illumina Multiplexed Sequencing (New England Biolabs, UK). The obtained root RNA library was sequenced using 150bp Paired-end chemistry in NextSeq 500 sequencing platform (Illumina, USA). De-novo transcriptome assembly was performed using Trinity 2.0 (default k-mers i.e 25. Trinity). Functional Annotation for clustered transcripts were analysed by the homology search against Viridiplantae dataset of the Uniprot database using BLAST-2.5.03. Pathway analysis was done using KAAS 4 Server of KEGG database to derive the secondary metabolite pathway and predict the gene transcripts involved in their biosynthesis.

\section{Statistical analysis}

All the experiments on antioxidant and cytotoxicity assay were performed in triplicate and the results were expressed as mean \pm S.D. Analysis of variance (ANOVA) was used to calculate the statistical significance of 
differences between groups, followed by Bonferroni test for multiple comparisons among groups using GraphPad Prism v.6. ${ }^{22} \mathrm{P}<0.05$ were considered as statistically significant.

\section{RESULTS}

\section{Total Phenolic content in extracts}

The total phenolic content was determined in ethanolic extracts of P.zeylanica and expressed as gallic acid equivalence in 100gm of the tissue extract. The phenolic content in root extract was found to be significantly higher $(17.5 \% \mathrm{w} / \mathrm{w})$ in comparison to stem $(2.09 \% \mathrm{w} / \mathrm{w})$ and leaf tissues $(1.39 \% \mathrm{w} / \mathrm{w})$. The high phenolic content in the extracts of P.zeylanica is suggestive of its antioxidant potential.

\section{HPTLC quantification of Plumbagin in tissue extracts}

Plumbagin is one of the well-known bio-active components in P. zeylanica ${ }^{8}$ and its spectral characteristics was analyzed at $265 \mathrm{~nm}$ and $419 \mathrm{~nm}$ (data not shown). Plumbagin was quantified in root, stem and leaf extracts using HPTLC where strong peak for plumbagin was observed at $419 \mathrm{~nm}$. Under the separation conditions used and visualized at $265 \mathrm{~nm}$, standard Plumbagin was eluted with a retention factor $0.65 \pm 0.02$ (Figure 1A) and showed a good linearity $\left(\mathrm{R}^{2}=0.995\right)$ in the concentrations of $400-1000 \mathrm{ng} / \mathrm{spot}$. The densiometric scanning followed by peak integration at wavelength of $419 \mathrm{~nm}$ showed the presence of plumbagin at the same $R_{f}$ value $\left(R_{f}=0.65\right)$ in all the three extracts of leaf, stem and root of P.zeylanica as shown in Figure 1B. The quantitation analysis revealed the amount of plumbagin in root, stem, leaf extracts as $1.3 \% \mathrm{w} / \mathrm{w}, 0.2 \% \mathrm{w} / \mathrm{w}$ and $0.00007 \% \mathrm{w} / \mathrm{w}$ respectively. In the present study, the maximum quantity of plumbagin was observed in the root extract $(1.3 \% \mathrm{w} / \mathrm{w})$, which is in agreement with the values reported earlier in P.zeylanica. ${ }^{23,24}$ The amount of plumbagin increased proportionately in the extracts spiked with plumbagin, which further confirmed the presence of plumbagin in all the three tissue extracts. The quantification result revealed the tissue dependent variation in the concentration of plumbagin of P.zeylanica, which in turn could influence the pharmacological activity. ${ }^{25}$ The quantification results also suggest that quantity of plumbagin in aerial part is contributed maximum by the stem tissue of P. zeylanica $(0.2 \%)$.

\section{DPPH radical scavenging assay}

The antioxidant capacity of plant extract depends on the hydrogen donating ability of phenols and flavonoids present. ${ }^{26}$ In the present study, all the three ethanolic extracts of P.zeylanica showed dose-dependent scavenging of free radicals. The total tissue extract showed a significant antioxidant $(\mathrm{P}<0.05)$ activity, wherein ethanolic root extract exhibited highest free radical scavenging activity (IC50 of $3.99 \mu \mathrm{g} / \mathrm{ml}$ ) in comparison with stem $(\mathrm{IC} 50=18.06 \mu \mathrm{g} / \mathrm{ml})$ and leaf $(\mathrm{IC} 50=35.85 \mu \mathrm{g} / \mathrm{ml})$ as illustrated in Figure 2A. These radical scavenging potential of the total extract was normalized with the quantity of plumbagin in extract and are plotted as function of plumbagin concentration of P.zeylanica (Figure 2B). The root extract containing $1.3 \% \mathrm{w} / \mathrm{w}$ plumbagin exhibited the antioxidant activity $(\mathrm{IC} 50=0.08 \mu \mathrm{g})$ and stem extract $(0.2 \% \mathrm{w} / \mathrm{w}$ plumbagin $)$ showed IC50 value of $0.05 \mu \mathrm{g}$, while leaf extract demonstrated IC50 value of $0.000003 \mu \mathrm{g}$. The standard pure plumbagin revealed strong antioxidant potential with an IC50 value of $0.92 \mu \mathrm{M}$ i.e. $0.16 \mu \mathrm{g} / \mathrm{ml}$ as shown in Figure 2C. The root extract with maximum phenolic content (17.5\%) showed significant antioxidant activity which prompted to carry out RNA sequencing in root tissues of $P$. zeylanica. Transcriptome analysis revealed some of the gene transcripts reported for antioxidant potential are found expressing in root tissues of P.zeylanica. Some of the specific antioxidant enzymes namely Catalase, Superoxide dismutase and Peroxidases have been identified in root tissues of $P$. zeylanica. The functional annotation
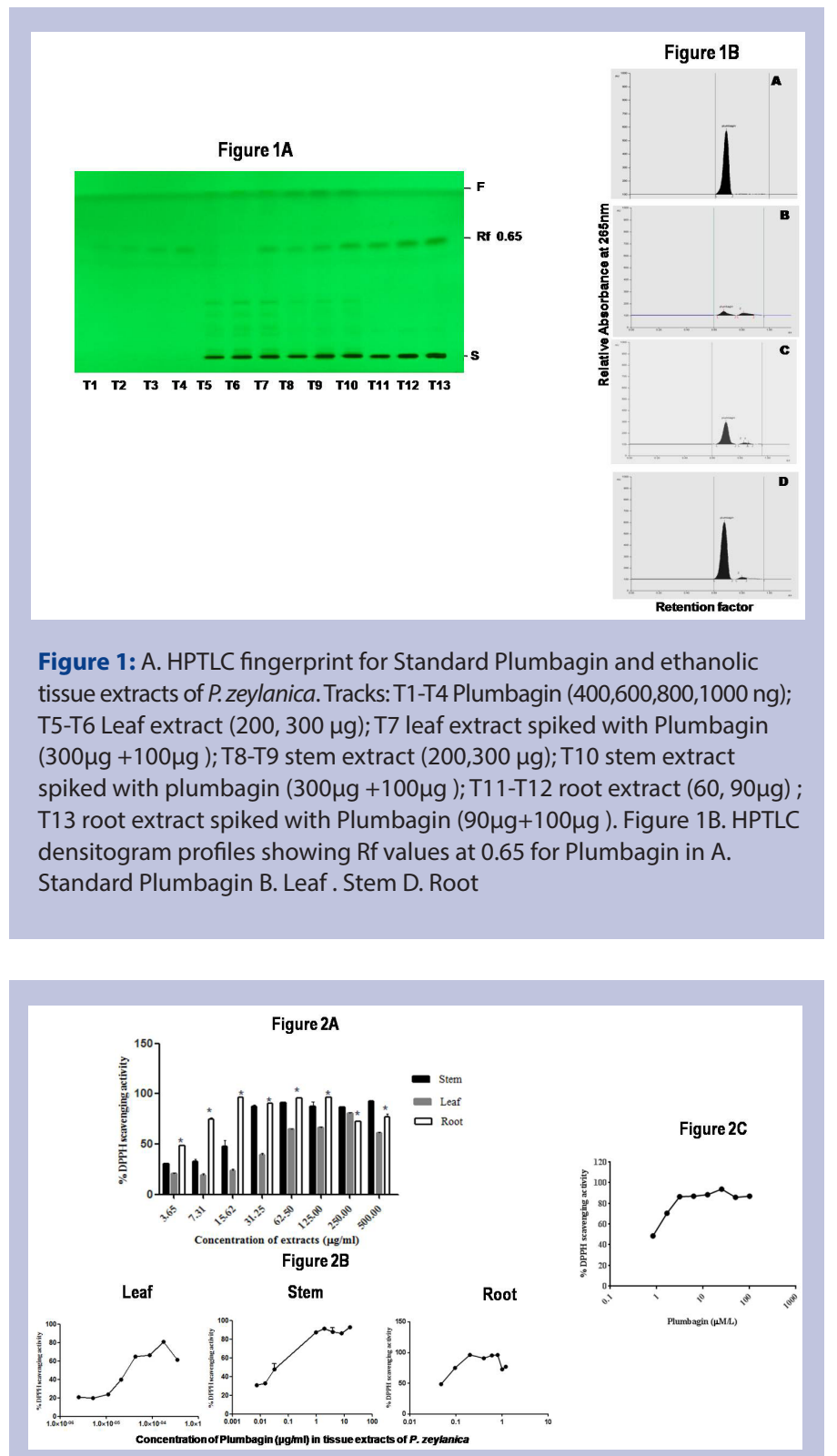

Figure 2: A. Free Radical scavenging activity in different total tissue extracts of $P$. zeylanica measured using DPPH assay. \% scavenging activity values are represented as Mean $\pm 1 S D(n=3)$. ${ }^{*} P<0.001$ as compared to leaf vs root). Figure 2B. Antioxidant potential of the extracts of P. zeylanica plotted as a function of Plumbagin content in the extracts. Figure 2 C. Free Radical scavenging activity of pure Plumbagin

of transcripts using COG classification revealed the transcripts of the enzymes with their unique protein ID for Catalase [Cg10256], Catalase (peroxidase I) [RSc0776], Glutathione peroxidase [RSc2674], Superoxide dismutase [SPAC1486.01] and $\mathrm{Cu} / \mathrm{Zn}$ superoxide dismutase [Rv0432] as listed in Table 1. Preliminary analysis of the root transcriptome carried out here illustrates only the antioxidant transcripts expression in root tissues of $P$. zeylanica. However, the detailed analysis of these antioxidant enzymes during defense against target cell need to be explored in detail to understand the translationary effect of the expressed enzyme transcripts for antioxidant potential. 


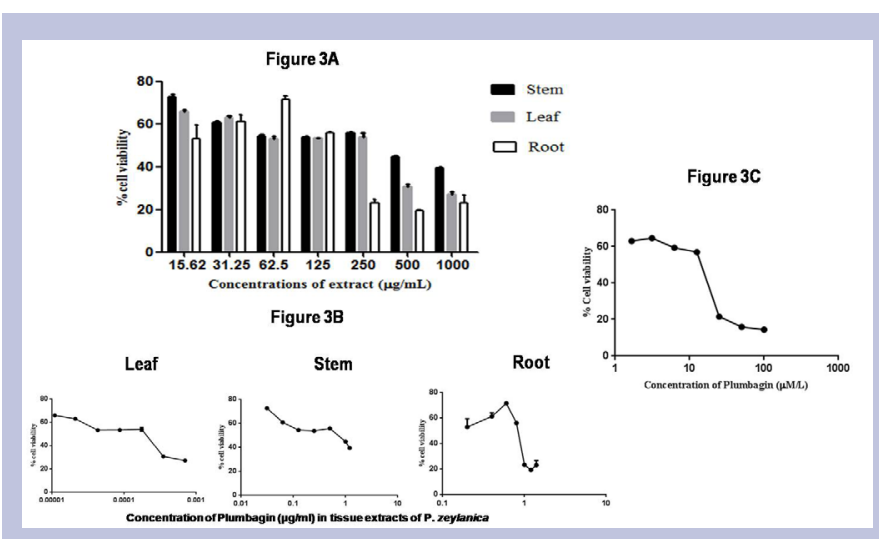

Figure 3: A. Cytotoxic effects of total tissue extracts of $P$. zeylanica studied using MTT assay. Values plotted are mean $\pm 1 S D(n=3)$. Figure 3B. Cytotoxic effects of the extracts of $P$. zeylanica plotted as a function of Plumbagin content in the extracts. Values plotted are mean $\pm 1 S D(n=3)$. Figure 3C. Cytotoxic effects of pure Plumbagin

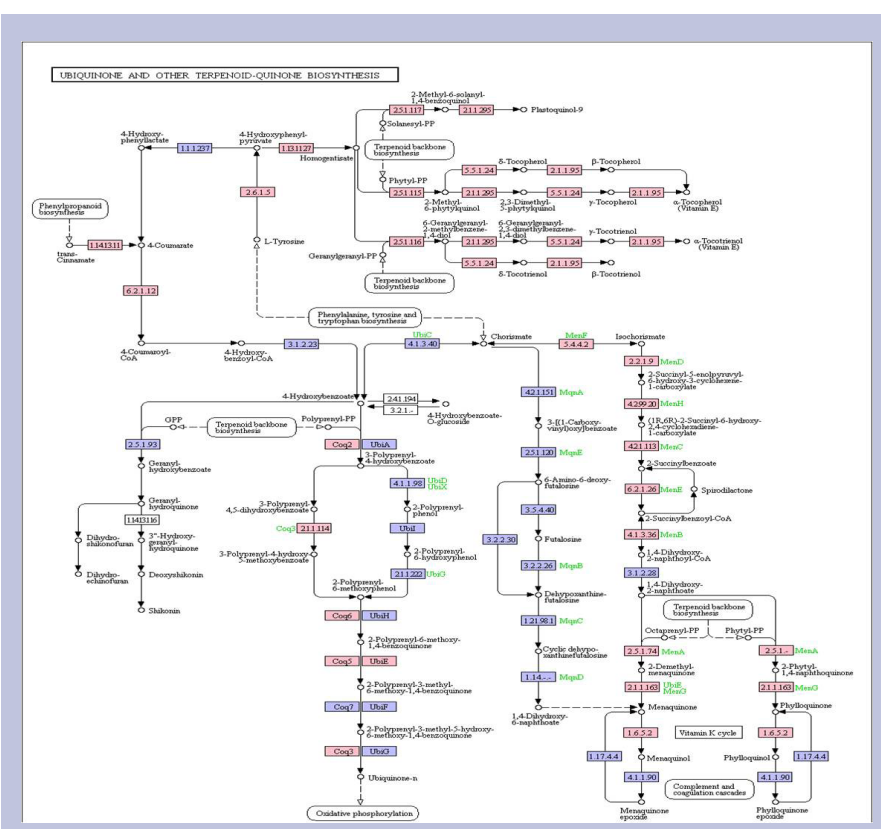

Figure 4: Terpenoid Quinone Pathway Map derived from root transcriptome of $P$. zeylanica using KAAS 4. The pathway map without color codes represents the original biosynthesis pathway obtained using KegSketch tool of KAAS database. Blue boxes represent reference pathway (KO) hyperlinked to KO entries selected from the original pathway in KEGG database and green colored genes represent organism specific pathway indicating the presence of genes in the transcriptome of P. zeylanica

\section{Cytotoxic activity}

P.zeylanica tissue extracts produced cytotoxic effect with IC50 values of $379.50 \mu \mathrm{g}$ for stem, $274.97 \mu \mathrm{g}$ for leaf and $164.5 \mu \mathrm{g}$ for root tissues on A549 human lung carcinoma cells (Figure $3 \mathrm{~A}$ ). The ethanolic root extract demonstrated more potent inhibition and dose-dependent reduction in the mitotic activity on A549 cells at $<200 \mu \mathrm{g} / \mathrm{ml}$ ( $50 \%$ inhibitory concentrations) in comparison to stem and leaf extract. The maximum cytotoxic effect exhibited by P.zeylanica root extract with high plumbagin (1.3\%) on A549 cells clearly substantiates anticancer properties of plumbagin as reported in other cancer cell lines. ${ }^{27,28}$ Comparative analysis on the cytotoxic effect normalized to plumbagin content in all the three extract predicted IC50 values for stem extract at $0.70 \mu \mathrm{g}$, leaf extract at $0.00023 \mu \mathrm{g}$ and $0.20 \mu \mathrm{g}$ in root extract as indicated in Table 2 (Figure 3B). The standard Plumbagin revealed $50 \%$ inhibitory concentration at $13.64 \mu \mathrm{M}$ i.e., $2.56 \mu \mathrm{g}$ and exhibited similar plateau effect as in root tissue at higher concentration (Figure 3C) indicating that it is necessary to determine optimum concentration of plumbagin for evaluating cytotoxicity.

\section{RNA sequencing Analysis in root tissues of P.zeylanica}

Paired end sequencing of the root cDNA library using Illumina NextSeq 500, generated 19 million reads with average length of $150 \mathrm{bp}$. De-novo transcriptome assembly and clustering resulted in $1,18,365$ unique transcripts, out of which 67570 transcripts could be annotated. In total, $57 \%$ of transcripts were functionally annotated using BLAST2.5.03 at high confidence level (e1-5). These transcripts were subjected to pathway analysis using KAAS 4 database. Eudicot plants in the KAAS 4 server were considered as reference organisms for pathway identification. From the root transcriptome of P. zeylanica, we have identified distinct secondary metabolite pathway genes mapped to the reference pathway in KAAS database. Many secondary metabolite pathways have been derived, out of which terpenoid-quinone biosynthesis pathway is shown in Figure 4 that represent enzymes and transcripts involved in phenyl propanoid and quinine metabolism. Plumbagin, a naphthoquinone is one of the important secondary metabolites in P. zeylanica, synthesized in the roots and demonstrate wider pharmacological activity. ${ }^{6}$ The quinone pathway in plants is also reported to have role in antioxidant defense. ${ }^{29}$ The colored codes on the pathway map have been computationally generated, where white boxes are hyperlinked to KO, ENZYME, and REACTION entries in metabolic pathways. The enzymes marked green in the terpenoid-quinone pathway map (Figure 4) represents genes (MenA-MenH and UbiE) involved in the biosynthesis of naphthoquninone. Menaquinone epoxide and Phylloquinone epoxide are some of the key gene transcripts identified that leads to metabolism of terpenoids and polyketides, which are reported to be unique to the plant specific secondary metabolite biosynthesis pathway. ${ }^{30}$

\section{DISCUSSION}

It is well established that among the composition of phyto-constituents, secondary metabolites of the plants play a vital role in determining the bio-efficacy of medicinal plants. ${ }^{31,6}$ Further, the isolation of secondary metabolites are known to vary with the extraction process and tissue parts of the plants. ${ }^{12,13}$ Comparative phytochemical evaluation in different tissue extracts of P.zeylanica revealed that the quantity of phyto-constituents varied in different parts of the plant (Figure 1A and Table 2). In this study, quantification of plumbagin in three distinct tissues of P.zeylanica by HPTLC revealed that root extract contain maximum quantity, in comparison to leaf and stem extract. However, this finding is at variance with the previous report, where a high plumbagin content was found in aerial part as compared to the root of P.zeylanica, while tissues were not discriminated clearly. ${ }^{17}$ This discrepancy in the quantity of plumbagin could also be due to the difference in the adopted method, where the earlier study relied on estimating plumbagin through spectral absorbance $(520 \mathrm{~nm})$ while the present study used HPTLC quantification to resolve plumbagin precisely $(419 \mathrm{~nm})$.

In the present study, when we compare antioxidant potential in total tissue extracts with respective plumbagin content in extract, we could observe that plumbagin is not the sole determinant for imparting antioxidant potential in tissues of P.zeylanica. This could also be substantiated by the HPTLC quantification analysis where other phyto-constituents could be observed in leaf and stem tissue as shown in Figure 1A. The 
Table 1: Antioxidant enzyme transcripts identified in root transcriptome of P.zeylanica

\begin{tabular}{cccc}
\hline Gene transcripts & Protein Id & Identity with Reference Organism & Function Reported \\
\hline Catalase & Cgl0256 & $51 \%$ & Inorganic ion transport and metabolism \\
Catalase (peroxidase I) & RSc0776 & Corynebacterium glutamicum & Inorganic ion transport and metabolism \\
Glutathione peroxidase & RSc2674 & $65.38 \%$ & Post-translational modification, protein \\
turnover, chaperones
\end{tabular}

Table 2: Comparative Analysis of estimated Phyto-constituents and bio-efficacy evaluated in different tissue extracts of $P$. zeylanica

\begin{tabular}{ccccccc}
\hline Tissues & $\begin{array}{c}\text { Total Phenolic } \\
\text { content } \\
\text { (Gallic acid } \\
\text { equivalent) }\end{array}$ & $\begin{array}{c}\text { Quantity of } \\
\text { Plumbagin }\end{array}$ & $\begin{array}{c}\text { Extracts } \\
(\mu \mathrm{g} / \mathrm{mL})\end{array}$ & $\begin{array}{c}\text { Plumbagin } \\
\text { content in } \\
\text { extract }(\mu \mathrm{g} / \mathrm{mL})\end{array}$ & $\begin{array}{c}\text { Extracts } \\
(\mu \mathrm{g} / \mathrm{mL})\end{array}$ & $\begin{array}{c}\text { Plumbagin content in extract } \\
(\mu \mathrm{g} / \mathrm{mL})\end{array}$ \\
\hline Root & $17.5 \%$ & $1.3 \%$ & 3.99 & 0.08 & 164.5 & 0.20 \\
Stem & $2.09 \%$ & $0.2 \%$ & 35.85 & 0.05 & 379.50 & 0.70 \\
Leaf & $1.39 \%$ & $0.00007 \%$ & 18.06 & 0.000003 & 274.97 & 0.0002 \\
\hline
\end{tabular}

results suggest that besides plumbagin, other phyto-constituents also play a vital role equally if not more to exert the bio-efficacy as observed in leaf tissues with negligible plumbagin $(0.00007 \%)$. Although the total root extract contain maximum plumbagin and exhibited high antioxidant potential but the normalized plumbagin content in the root extract showed less scavenging activity. These differences suggest that other phyto-constituents in root (17.5\% total phenolic compounds) might play a vital role in exerting the free radical scavenging activity.

Earlier studies have indeed shown that plumbagin in high concentration could be toxic to normal lymphocytes, whereas the ethanolic root extracts of Plumbago rosea possessing associated phyto-constituents in addition to plumbagin exhibited synergistic stronger anticancer effect with less toxicity. ${ }^{32}$ Intriguingly, the cytotoxicity exhibited by leaf extract normalized with plumbagin content was multi-folds higher in P.zeylanica indicating that other active phyto-constituent in leaf might have synergistic action or modulatory role to exhibit desired therapeutic properties. The selective toxicity of leaf extracts in normal cells needs to be investigated further to ascertain its anticancer potential with less side effects.

Plant extracts containing phenolic compounds could exhibit antioxidant activity as well as anticancer properties. ${ }^{33,34}$ At higher concentrations, phenolic compounds might act as pro-oxidants and alter the redox balance of tumor cells, thereby inducing apoptosis and cytotoxicity. ${ }^{35}$ In line with this, the total root extract of P.zeylanica at low concentrations exhibited high antioxidant activity with an IC50 value of $3.99 \mu \mathrm{g} / \mathrm{mL}$, while it was clearly cytotoxic at higher concentrations, with an IC50 value of $164.5 \mu \mathrm{g} / \mathrm{mL}$, which correlated well with the higher level of phenolic compounds found in the root (17.5\%).

Plumbagin, is one of the naphthoquinones synthesized and accumulated in the root tissue of $P$. zeylanica, ${ }^{36}$ which is partly responsible for the multiple biological effects. The anticancer potential of Plumbagin has been demonstrated in some of the human cancer cell lines. ${ }^{37,9,10}$ Since the root tissue of P. zeylanica exhibited strong antioxidant and cytotxic effects compared to other tissues, it prompted us to study the quinone biosynthesis pathway to identify naphthoquinones expressed in root tissue of $P$. zeylanica (Figure 4). Interestingly, the candidate gene transcripts of terpenoids and quinines identified in root transcriptome were found to be involved in naphthoquinone biosynthesis, which is one of the important secondary metabolite in root tissues. ${ }^{38}$ Hence, further analysis on the other secondary metabolite pathways derived from the root transcriptome could help to bring out some of the co-expressed candidate gene transcripts necessary for biosynthesis of naphthoquinones in P.zeylanica.

\section{CONCLUSION}

The strong antioxidant potential shown by the tissue extracts of $P$. zeylanica demonstrates its ability to protect the non-target (normal) cells against oxidative stress, while the cytotoxic effects suggest that it could inhibit the growth of cancerous cells. These effects exhibited by total leaf, stem and root extract of P.zeylanica also indicates the presence of more active lead compounds in addition to active principle plumbagin for demonstrating wider pharmacological activity. Hence, the identification of other bioactive compounds in leaf and stem might reveal therapeutic effects similar to plumbagin and/or augment the action of plumbagin in a synergistic manner. Hence, it suggest that extensive work on more number of tumor cell line, selective toxicity studies and in vivo experiments could help to bring out the application of P.zeylanica tissue extracts for anticancer therapies. 


\section{ACKNOWLEDGEMENT}

The author B Karpaga Raja Sundari acknowledges Research Grant from DST-National Post-Doctoral Fellowship. The Genomic Sequencing facility at M/s Genotypic Pvt. Ltd., Bangalore is greatly acknowledged for their support in RNA sequencing of samples.

\section{CONFLICT OF INTEREST}

The authors declare that they have no competing financial interests.

\section{ABBREVIATION USED}

DPPH: 2,2-diphenyl-1-picrylhydrazyl; MTT: 3-(4,5-dimethylthiazol2-yl)-2,5-diphenyltetrazolium bromide; IC $_{50}$ : half maximal inhibitory concentration; HPTLC: High Performance Thin Layer Chromatography; DMSO: Dimethyl sulfoxide; COG: Clusters of Orthologous Groups; KAAS: KEGG Automatic Annotation Server.

\section{REFERENCES}

1. Gostner JM, Wrulich OA, Jenny M, Fuchs D, Ueberall F. An update on the strategies in multicomponent activity monitoring within the phytopharmaceutical field. BMC complementary and alternative medicine. 2012;12(1):18.

2. Gupta AA, Siddiqui IR, Singh J. A new anthraquinone glycoside from the roots of Plumbago zeylanica. Indian J Chem. 2000;398:796- 798.

3. Pant M, Lal A, Rana S, Rani A. Plumbago zeylanica L.: a mini review. International Journal of Pharmaceutical Applications. 2012;3(3):399-405

4. Tilak JC, Adhikari S, Devasagayam TP. Antioxidant properties of Plumbago zeylanica, an Indian medicinal plant and its active ingredient, plumbagin. Redox report. 2004;9(4):219-27.

5. Subramaniya BR, Srinivasan G, Sadullah SS, Davis N, Subhadara LB, et al. Apoptosis inducing effect of plumbagin on colonic cancer cells depends on expression of COX-2. PloS one. 2011 Apr 29:6(4):e18695.

6. Jain P, Sharma HP, Basri F, Baraik B, Kumari S, et al. Pharmacological Profiles of Ethno-Medicinal Plant: Plumbago zeylanica L.-A Review. Int J Pharm Sci Rev Res. 2014;24:157-63.

7. Sao S, Dubey S. Antimicrobial Activity of Leaves Extract of Plumbago zeylanica Plant against Known Drugs. IJRSB. 2015;3(6):1-6.

8. Ding Y, Chen ZJ, Liu S, Che D, Vetter M, Chang $\mathrm{CH}$. Inhibition of Nox-4 activity by plumbagin, a plant-derived bioactive naphthoquinone. Journal of pharmacy and pharmacology. 2005;57(1):111-6.

9. Lee JH, Yeon JH, Kim H, Roh W, Chae J, et al. The natural anticancer agent plumbagin induces potent cytotoxicity in MCF-7 human breast cancer cells by inhibiting a Pl-5 kinase for ROS generation. PLoS One. 2012;7(9):e45023.

10. Yan $\mathrm{CH}$, Li F, Ma YC. Plumbagin shows anticancer activity in human osteosarcoma (MG-63) cells via the inhibition of S-Phase checkpoints and downregulation of c-myc. International journal of clinical and experimental medicine. 2015:8(8):14432

11. Yan $\mathrm{CH}$, Li F, Ma YC. Plumbagin shows anticancer activity in human osteosarcoma (MG-63) cells via the inhibition of S-Phase checkpoints and down-regulation of c-myc. International journal of clinical and experimental medicine. 2015;8(8):14432

12. Reichelt M, Brown PD, Schneider B, Oldham NJ, Stauber E, et al. Benzoic acid glucosinolate esters and other glucosinolates from Arabidopsis thaliana. Phytochemistry. 2002;59(6):663-71.

13. Chen F, Tholl D, D'Auria JC, Farooq A, Pichersky E, Gershenzon J. Biosynthesis and emission of terpenoid volatiles from Arabidopsis flowers. The Plant Cell. 2003;15(2):481-94

14. Anandan A, Eswaran R, Doss A, Sangeetha G, Anand SP. Chemical compounds investigation of Lucas aspera leaves-a potential folklore medicinal plant. Asian Journal of Pharmaceutical and Clinical Research. 2012;5(1):86-8.

15. Bailie A, Renaut S, Ubalijoro E, Guerrero-Analco JA, Saleem A, et al. Phytogeographic and genetic variation in Sorbus, a traditional antidiabetic medicineadaptation in action in both a plant and a discipline. PeerJ. 2016;4:e2645.

16. Raya KB, Ahmad SH, Farhana SF, Mohammad M, Tajidin NE, et al. Changes in phytochemical contents in different parts of Clinacanthus nutans (Burm. f.) lindau due to storage duration. Bragantia. 2015;74(4):445-52.

17. Cunningham $A B$. The role of ethnobotany and indigenous knowledge in conservation of plant genetic resources. Dinteria. 1992;23:119-31.

18. Dohare B, Jain B, Khare S, Jain K. Comparative Estimation of Plumbagin in Aerial and Root Part of Plumbago zeylanica Using UV-Visible Spectrophotometric. UK. J. Pharm. Biosci. 2015;3:09-14.

19. Yang L, Ding G, Lin $H$, Cheng $H$, Kong $Y$, Wei $Y$, et al. Transcriptome Analysis of Medicinal Plant Salvia miltiorrhiza and Identification of Genes Related to Tanshinone Biosynthesis. Corrected and republished from: PLoS ONE. 2013;8:10.1371.

20. Unamba $\mathrm{Cl}$, Nag A, Sharma RK. Next generation sequencing technologies: the doorway to the unexplored genomics of non-model plants. Frontiers in plant science. 2015 Dec;6:1074

21. Srirama R, Deepak HB, Senthilkumar U, Ravikanth G, Gurumurthy BR et al. Hepatoprotective activity of Indian Phyllanthus. Pharmaceutical biology. 2012;50(8):948-53.

22. Sofi MS, Sateesh MK, Bashir M. Screening of the ethnobotanicals against MDA-MB-231 and MCF-7 breast cancer cell lines. International Journal of Phytopharmacy. 2014;4(6):140-7.

23. Sannigrahi S, Mazuder UK, Pal DK, Parida S, Jain S. Antioxidant potential of crude extract and different fractions of Enhydra fluctuans Lour. Iranian journal of pharmaceutical research: IJPR. 2010;9(1):75.

24. Chauhan M. A review on morphology, phytochemistry and pharmacological activities of medicinal herb Plumbago Zeylanica Linn. Journal of Pharmacognosy and Phytochemistry. 2014;3(2).

25. Rakhshi I, Pawar RK, Singh K. C3 Development of HPTLC Method For The Determination Of Plumbagin In Chitrak Haritak - An Ayurvedic Formulation. Asian J Pharm Clin Res. 2015:3:24-31.

26. Kishore N, Mishra BB, Tiwari VK, Tripathi V. An account of phytochemicals from Plumbago zeylanica (Family: Plumbaginaceae): A natural gift to human beings. Chron Young Sci. 2012;3(3):178-98

27. Shyur LF Tsung JH, Chen JH, Chiu CY, Lo CP. Antioxidant properties of extracts from medicinal plants popularly used in Taiwan. Int. J. Appl. Sci. Eng. 2005;3(3):195-202.

28. Alawode TT. An overview of the anti-cancer properties of some plants used in traditional medicine in Nigeria. International Research Journal of Biochemistry and Bioinformatics. 2013;3(1):7-14.

29. Aditya VS, Kumar NL, Mokkapati AL. In vitro anti-cancer activities of few plant extracts against MCF-7 and HT-29 cell lines. Int J Pharma Sci. 2013;3:185-8.

30. Akula R, Ravishankar GA. Influence of abiotic stress signals on secondary metabolites in plants. Plant signaling \& behavior. 2011;6(11):1720-31.

31. Gross J, Cho WK, Lezhneva L, Falk J, Krupinska K, et al. A plant locus essential for phylloquinone (vitamin K1) biosynthesis originated from a fusion of four eubacterial genes. Journal of Biological Chemistry. 2006;281(25):17189-96.

32. Farombi EO. African indigenous plants with chemotherapeutic potentials and biotechnological approach to the production of bioactive prophylactic agents. African journal of biotechnology. 2003;2(12):662-71.

33. Anuf AR, Ramachandran R, Krishnasamy R, Gandhi PS, Periyasamy S. Antiproliferative effects of Plumbago rosea and its purified constituent plumbagin on SK-MEL 28 melanoma cell lines. Pharmacognosy research. 2014;6(4):312.

34. Deep G, Dhiman M, Rao AR, Kale RK. Chemopreventive potential of Triphala (a composite Indian drug) on benzo (a) pyrene induced forestomach tumorigenesis in murine tumor model system. Journal of experimental \& clinical cancer research: CR. 2005;24(4):555-63.

35. Darvesh AS, Bishayee A. Chemopreventive and therapeutic potential of tea polyphenols in hepatocellular cancer. Nutrition and cancer. 2013;65(3):329-44.

36. Massaoka MH, Matsuo AL, Figureueiredo CR, Farias CF Girola N, et al. Jacaranone induces apoptosis in melanoma cells via ROS-mediated downregulation of Akt and p38 MAPK activation and displays antitumor activity in vivo. PLoS One. 2012;7:e38698. Cited in Pubmed; PMID 22701695.

37. Van der Vijver LM. Distribution of plumbagin in the Plumbaginaceae. Phytochemistry. 1972;11:3247-3248.

38. Gomathinayagam R, Sowmyalakshmi S, Mardhatillah F, Kumar R, Akbarsha MA, et al. Anticancer mechanism of plumbagin, a natural compound, on non-small cell lung cancer cells. Anticancer research. 2008;28(2A):785-92.

39. Renuga G, Babuthandapani A. Evaluation on antimicrobial potential of root extracts Plumbago zeylanica L against human intestinal microflora. Int J Pharm Biol Res. 2013;4:146-58. 
GRAPHICAL ABSTRACT

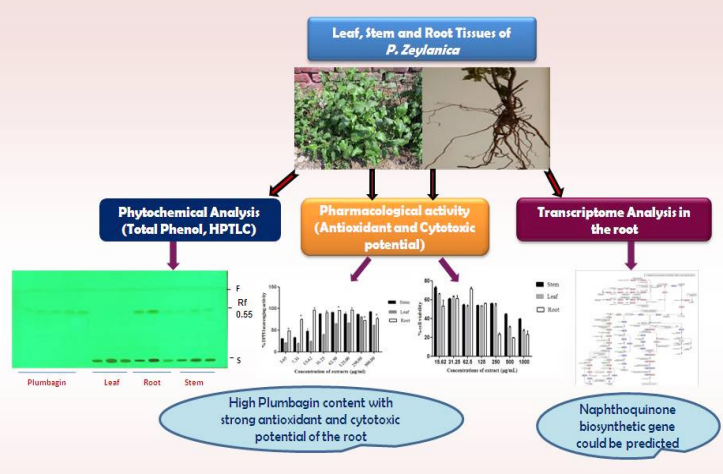

AUTHOR PROFILE

\section{HIGHLIGHTS OF PAPER}

- The ethanolic root extract of P. zeylanica with high plumbagin content demonstrated maximum antioxidant and cytotoxic potential

- The strong antioxidant potential shown by the tissue extracts of $P$. zeylanica demonstrates its ability to protect the non-target (normal) cells against oxidative stress, while the cytotoxic effects suggest that it could inhibit the growth of cancerous cells.

- Bio-efficacy of leaf tissue plotted as function of Plumbagin content revealed maximum pharmacological activity suggesting synergistic action of other bio-active molecules

- Preliminary analysis on the quinone pathway derived from the root transcriptome predicted gene transcripts for biosynthesis of naphthoquinone.

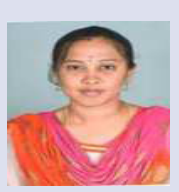

Dr. B. Karpaga Raja Sundari: She is currently working as DST-National Post Doctoral Fellow in the Herbal and Indian Medicine Research laboratory, Central Research Facility, Sri Ramachandra University, Chennai. She holds $\mathrm{Ph}$.D in Forest Biotechnology and has 8 years of research experience in Plant Biotechnology. Her research focuses towards functional genomics and molecular biology of medicinal plants involving isolation and characterization of candidate genes harboring economically important traits. RNA sequencing and transcriptome analysis in medicinal plants is her current area of research to unravel secondary metabolite biosynthetic pathway networks for exploring candidate genes with wider pharmacological activity. She has eight research publications to her credit in peer reviewed Journals and three Book Chapters. She has presented her research findings in various national and international conferences and bagged Best Paper and Poster awards.

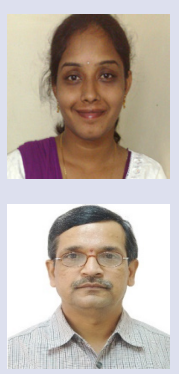

Srivani Telapolu: She is working as a research scholar and pursuing PhD at Herbal and Indian Medicine Research laboratory, Central Research Facility, Sri Ramachandra University, Chennai. She holds master degree in Pharmacognosy and has 4 years of research experience in herbal drug quality control. Currently she is working on development and standardization of herbal supplements for diabetes mellitus. She has participated in many international and national conferences and won best paper awards.

Dr. B.S. Dwarakanath: $\mathrm{He}$ is currently Professor (Research) at Sri Ramachandra University, Chennai. He has made outstanding contributions in developing mechanism based approaches for radiation countermeasure and cancer therapy, besides engineering the development of 2-deoxy-D-glucose (2-DG) as an adjuvant in cancer therapy. He has mentored post-doctoral fellows and doctoral as well as Master degree students from many Universities and national institutes. He serves on the editorial board of seven international journals and as reviewer for 44 journals. He has published more than 240 papers in peer reviewed journals, books and monographs.

Prof. S.P.Thyagarajan: Prof. Thyagarajan, was the Vice-Chancellor of the University of Madras during 2003-2006,

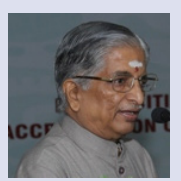
and is currently Professor of Eminence \&Dean (Research) at Sri Ramachandra University, Chennai. He has been conferred with several Fellowship titles including those by National Academy of Sciences and National Academy of Medical Sciences. He has 46 years of teaching and research experience and successfully completed 60 research projects funded by national and inter-national funding agencies. He has published 340 research papers and 16 books in the area of infectious diseases and Drug development from Natural products; He serves as member of several expert committees of UGC, ICMR, DST.,DBT, DOD, Ministry of Health, WHO etc., He has guided 32 candidates for their Ph.D. He is the inventor of a patented drug for the treatment of Chronic jaundice, called Hepatitis-B from the Indian medicinal plant, Phyllanthus amarus, [Kizhanelli in Tamil], which has already been marketed by an University-Industry agreement under the brand name "VIROHEP" by Rallis India Pharmaceuticals/ Shreya Life Sciences, Mumbai.

Cite this article : Sundari BKR, Telapolu S, Dwarakanath BS, Thyagarajan SP. Cytotoxic and Antioxidant Effects in Various Tissue Extracts of Plumbago zeylanica: Implications for Anticancer Potential. Pharmacog J. 2017;9(5):706-12. 